\title{
Study on the Influencing Factors of the Particle Size Distribution of Emulsion for ASP Flooding
}

\author{
Wenling Song ${ }^{*}$, Li-Juan Zhao, Zhigang Huang and Wei Dou
}

Petroleum Engineering College, Northeast Petroleum University, Daqing 163318, China

\begin{abstract}
The particle size distribution of oil-water emulsion is one of important characteristics of emulsion for alkaline/surfactant/polymer (ASP) flooding. In this paper, the various factors on particle size distribution of oil-water emulsion are determined by using MS 2000 Micro laser particle size analyzer, the result showed that the emulsion particles became fining by the added surfactant, but the surfactant concentration has little effects on particle size of emulsions. With the salinity increase, the diameters of emulsion particles increased. The particle size becomes larger with the addition of polymer. With the increase of polymer concentration, the diameters of emulsion particles increased and the size distribution turned wider.
\end{abstract}

Keywords: Emulsion, laser particle size analyzer, particle size distribution, polymer, surfactant.

\section{INTRODUCTION}

Crude oil emulsion is a liquid - liquid dispersion, emulsion droplet size characteristics is one of the important properties of emulsion, The main parameters of the particle size characteristics, including size and size distribution. The particle size characteristics can not only determine the composition character of crude oil emulsion dispersed phase from the microscopic, but also describes the processes of crude oil emulsion flocculation and coalescence from the macroscopic. Meanwhile, the overall properties of the crude oil emulsion, such as viscosity, viscoelasticity, etc., are also closely related to its particle size characteristics [1]. The measurement of emulsion droplet size distribution may use microscopic statistical method, laser scattering method, ultrasonic method and ultracentrifugation [2], and the most widely used measurement is laser scattering method. In this paper, the various factors on particle size distribution of oilwater emulsion are carried out using MS 2000 Micro laser particle size analyzer.

\section{EXPERIMENTAL PART}

\subsection{Experimental Drugs and Equipment}

Crude oil, density is $0.846 \mathrm{~g} / \mathrm{cm}^{3}$; Heavy alkylbenzene sulfonate, Content of 50\%; Polymer, The molecular weight of 25 million; On-site sewage and water; Soda: Analytical reagent. Digital DC variable speeds agitator; MS 2000 Micro laser particle size analyzer; Electric oven thermostat blast; temperature controlled bath; measuring cylinder; $200 \mathrm{ml}$ beakers.

*Address correspondence to this author at the Petroleum Engineering College, Northeast Petroleum University, Daqing 163318, China;

Tel: +8613845932532; E-mail: 731329394@qq.com

\subsection{The Working Principle of Laser Particle Size Analyzer}

Laser diffraction method, also known as the small angle laser light scattering method, based on the Mie scattering theory completely. A certain laser wavelength is emitted by a $\mathrm{He}-\mathrm{Ne}$ laser, laser diffraction when it passed particles, the diffraction Angle of light associated with the particle size of particles, the larger the particles, the smaller the Angle of the diffraction of light. Different size particles of the diffraction of light falls on a different position, therefore, the position of the diffraction light can reflect the particle size. By appropriate light path allocation, on the other hand, for the same size of particles the diffraction of light falls on the same position, so after superposition of the intensity of the diffraction light reflects particles of relative to how much, through distribution on the different Angle of detector to determine the position of the diffraction light information and intensity information, then according to the Mie theory to calculate the particle size distribution $[3,4]$.

\subsection{Experimental Procedure}

According to the preparation of emulsion oil-water ratio is $98: 2$ with $200 \mathrm{ml}$ beaker. Put active aqueous solution and dehydrated crude oil at $45^{\circ} \mathrm{C}$ oven for 2 hours, beaker heating first and constant at $45^{\circ} \mathrm{C}$, then use beaker to take preparation chemical solution of volume $98 \%$, and then take the crude oil of volume $2 \%$. Put the ready beaker fixed in $45^{\circ} \mathrm{C}$ constant temperature water bath, and then insert the agitator's head into the cup, stirring by a high-speed for 10 minutes. Under the high speed stirring of agitator, oil and water are emulsified.

\subsubsection{The Emulsion Particle Size Test}

Boot according to the instrument manual, second distilled water is injected in a $500 \mathrm{ml}$ beaker, the appropriate mixing speed is set. Then, the prepared emulsion was injected into 
the beaker to make the shading degree reach $10-20 \%$. After ultrasonic processing (can not only make the sample after adding, a beaker solution does not only produce obvious bubbles, but also makes the sample particles evenly distributed in the distilled water without settlement) test the particle size distribution of the sample.

\section{RESULTS AND ANALYSIS}

\subsection{Effect of Surfactant Concentration on Emulsion Particle Size Distribution}

From Table 1, it can be concluded that the emulsion system of different surfactant concentration on the particle size (D $(\mathrm{v}, 0.5)$ ) is very small, below $3 \mu \mathrm{m}$. Each concentration of emulsion particle size increase is not large. The particle value is about $0.7 \mu \mathrm{m}$ when the cumulative volume is $10 \%$, the particle size is below $20 \mu \mathrm{m}$ when the cumulative volume is $90 \%$. Active agent addition decreases the interfacial tension, and promotes the deformation of droplets, contributes to the formation of small size, at the same time, the presence of surfactant in the continuous phase in the form of micelles, can have the effect of solubilization of oil droplets, the emulsion particle size maybe become very small.

Fig. (1), a bipeaks particle size distribution curve phenomenon appeared, especially when surfactant concentration is $0.5 \%$, obviously, peaks appeared at $1.95 \mu \mathrm{m}$ and $14.2 \mu \mathrm{m}$ shows that close to the particle size of the two values of particle size. Bipeaks shows that uneven distribution of the emulsion, dispersion is not very good enough.

Table 1. Different surfactant concentration of emulsion particle size distribution.

\begin{tabular}{|c|c|c|c|c|}
\hline Surfactant Concentration (\%) & $\mathbf{D}[\mathbf{4 , 3}]$ & $\mathbf{D}(\mathbf{v}, \mathbf{0 . 1})$ & $\mathbf{D}(\mathbf{v}, \mathbf{0 . 5})$ & $\mathbf{D}(\mathbf{v}, \mathbf{0 . 9})$ \\
\hline \hline 0.1 & 6.99 & 0.77 & 2.59 & 16.43 \\
\hline 0.2 & 2.90 & 0.67 & 1.71 & 7.37 \\
\hline 0.3 & 4.66 & 0.76 & 2.28 & 12.85 \\
\hline 0.5 & 6.34 & 0.78 & 2.79 & 15.79 \\
\hline
\end{tabular}

Note: The table $\mathrm{D}[4,3]$ is derived from the average particle diameter of the volume distribution, the unit is $\mu \mathrm{m}, \mathrm{D}(\mathrm{v}, 0.1), \mathrm{D}(\mathrm{v}, 0.5), \mathrm{D}(\mathrm{v}, 0.9)$ is the total volume of the particles to $10 \%, 50 \%, 90 \%$, corresponding to the particle size, Tables $\mathbf{2}$ and $\mathbf{3}$ in the same way.

\subsection{The Water Quality to the Influence of Emulsion Particle Size Distribution}

With different water quality preparation of emulsion particle size distribution is shown in Table 2. Sewage preparation of emulsion particle size is larger than that of clear water, increased nearly doubled. The clear water salinity is $222 \mathrm{mg} / \mathrm{L}$, the produced water salinity is 4646 $\mathrm{mg} / \mathrm{L}$, The increase of various inorganic salt in water phase, increased the variety of ion content, makes the adsorption on the droplets around the ionic strength increases, and the increase of salinity reduce oil-water interfacial film strength, is advantageous to the oil droplet coalescence and the emulsion particle size bigger.

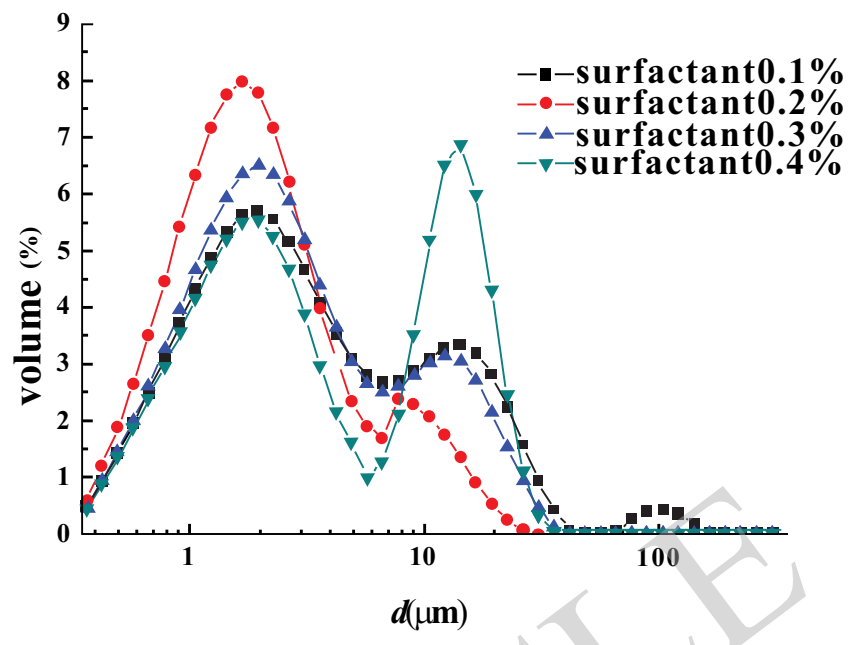

Fig. (1). Different concentration of surfactant emulsion particle size distribution curve.

Table 2. Different water qualities of emulsion particle size distribution.

\begin{tabular}{|c|c|c|c|c|}
\hline Water Quality & $\mathbf{D}[\mathbf{4 , 3}]$ & $\mathbf{D}(\mathbf{v}, \mathbf{0 . 1})$ & $\mathbf{D}(\mathbf{v}, \mathbf{0 . 5})$ & $\mathbf{D}(\mathbf{v}, \mathbf{0 . 9})$ \\
\hline \hline Clear water & 6.17 & 0.82 & 4.80 & 13.72 \\
\hline Sewage & 9.62 & 0.97 & 8.69 & 19.64 \\
\hline
\end{tabular}

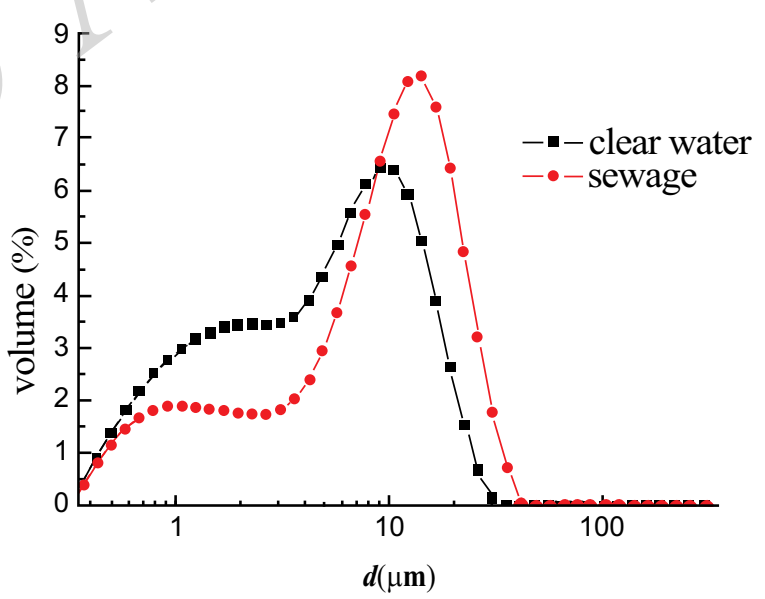

Fig. (2). The size of emulsion particle size distribution curves for water with different water quality.

Fig. (2) is the preparation of emulsion particle size under two kinds of salinity distribution curve. Particle size distribution curve similar to Gaussian distribution, two kinds of emulsion dispersion system are normal. Sewage preparation of emulsion particle size distribution curve peak shifts to the right, and the peak is a little higher, it also suggests that the sewage preparation of emulsion particle size is greater than water preparation of emulsion particle size values.

\subsection{Polymer Concentration on the Influence of Emulsion Particle Size Distribution}

Table $\mathbf{3}$ is active water adding different concentration of polymer and crude oil emulsion formed by particle size distribution, in the same situation of alkali concentration $(1.2 \%)$ and surfactant concentration $(0.3 \%)$. The emulsion 
particle size increases with the increase of the concentration of the polymer, and the amplitude value is relatively large, and the addition of polymer emulsion particle size increases (Without the addition of polymer, particle size is $2.28 \mu \mathrm{m}$ ). With the increase of the concentration of polymer, the emulsion median particle size increased from $7.12 \mu \mathrm{m}$ to $78.49 \mu \mathrm{m}$. There are two reasons for this: firstly, in the process of crude oil emulsion to form water-in-oil microemulsion phase and polymer adsorption on the oilwater interface, the bending modulus of the improved interfacial film, against the spontaneous curvature of interfacial film change; Secondly, under the certain stirring intensity, along with the increase of polymer concentration, improved the water phase viscosity, that against shear dispersion of droplets, so the formation of the droplet diameter increase gradually.

Table 3. Different polymer concentration of emulsion particle size distribution.

\begin{tabular}{|c|c|c|c|c|}
\hline Polymer Concentration (mg/L) & $D[\mathbf{4 , 3}]$ & $D(\mathbf{v}, \mathbf{0 . 1})$ & $D(\mathbf{v}, \mathbf{0 . 5})$ & $\mathbf{D}(\mathbf{v}, \mathbf{0 . 9})$ \\
\hline \hline 100 & 9.00 & 0.78 & 7.12 & 20.30 \\
\hline 500 & 41.43 & 2.52 & 32.14 & 92.21 \\
\hline 1000 & 64.80 & 14.45 & 55.70 & 126.94 \\
\hline 2000 & 90.34 & 16.14 & 78.49 & 185.01 \\
\hline
\end{tabular}

As shown in Fig. (3), with the increase of polymer concentration, the emulsion particle size distribution curve peak moves to the right gradually, and the particle size distribution widened gradually, consistent with the bigger particle size.

\section{CONCLUSION}

(1) The concentration of surfactant effects a little on the emulsion particle size distribution, but the surfactant has lower interfacial tension and solubilization ability which make the emulsion particle size much smaller.

The emulsion particle size becomes larger with the increase on salinity.
With the increase in polymer concentration, particle size of emulsion becomes larger, and the particle size distribution wider.

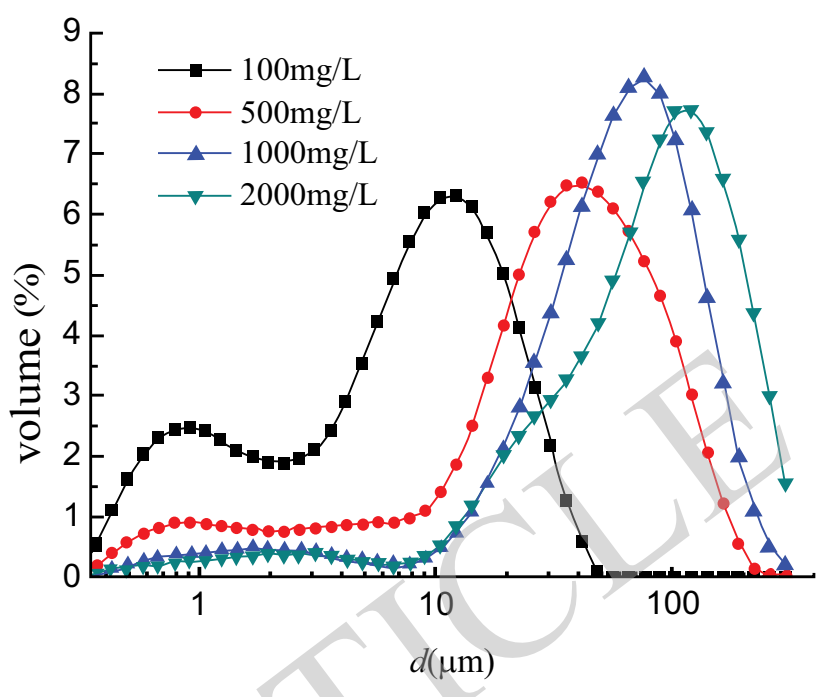

Fig. (3). Polymer concentration of emulsion particle size distribution curve.

\section{CONFLICT OF INTEREST}

The authors confirm that this article content has no conflict of interest.

\section{ACKNOWLEDGEMENTS}

Declared none.

\section{REFFERENCES}

[1] Beche, P. Emulsion: Theory and Practice. Science Press: Beijing, 1978.

[2] David, T.; Mukul, M.S. Factors controlling the stability of colloidstabilized emulsions III measurement of the rheological properties of colloid-laden interfaces. J. Colloid. Interf. Sci., 1995, 171, 456462.

[3] Malvern Analysis Instrument. Software for MASTERSIZER. Malvern Analysis Instrument: British, 2000.

[4] Yingzi, T.; Kefu, C.; Heng, Z. The use and test analysis of Malvern granulometer. Made China, 2003, 22(12), 33-35. 